Nikolina N. Zobenica

Univerzitet u Novom Sadu

Filozofski fakultet

nikolina@ff.uns.ac.rs
UDK 81 '255.4

Originalan naučni rad

10.19090/mv.2016.7.423-439

\title{
PROJEKTNA NASTAVA KAO VANNASTAVNA AKTIVNOST: PREVOĐENJE TEKSTOVA KARLA MARKUSA GAUSA O DUNAVU
}

\begin{abstract}
APSTRAKT
Kad je reč o univerzitetskoj nastavi prevođenja, još uvek se najčešće koristi tradicionalni nastavni koncept (frontalni): prevođenje kod kuće ili na času - čitanje prevoda na času - analiza i diskusija - vrednovanje prevoda. Tekstovi koji se prevode su raznoliki (stručni, upotrebni ili književni), a njihov izbor uglavnom zavisi od predmetnog nastavnika. Zbog ograničenog vremenskog okvira najčešće se prevodi nekoliko pasusa iz nekog teksta koji nije poznat u celosti, te učenici ili studenti nemaju uvid u kontekst odlomka. Postoje, međutim, i moderniji nastavni koncepti, odnosno inovativni modeli nastave koji mogu da se primene u nastavi prevođenja. Jedan od inovativnih metoda je i projektna nastava. Na Odseku za germanistiku Filozofskog fakulteta u Novom Sadu organizovan je prevodilački projekat kao vannastavna aktivnost u kojoj su učestvovali studenti osnovnih, master i doktorskih studija Nemačkog jezika i književnosti, koji su zajednički (timski) prevodili dva eseja sa nemačkog na srpski jezik. U ovom radu se daje prikaz projektne nastave, njene organizacije, toka i rezultata. Cilj je da se prikažu preduslovi, prednosti, ali i ograničenja ovakvog nastavnog koncepta kao vannastavne aktivnosti na univerzitetu.
\end{abstract}

Ključne reči: projektna nastava, prevodilački projekat, vannastavna aktivnost, Karl Markus Gaus, književno prevođenje.

\section{PROJECT METHOD AS AN EXTRACURRICULAR ACTIVITY: TRANSLATING KARL MARKUS GAUß' TEXTS ON DANUBE}

\begin{abstract}
In teaching translation at universities, instructors still mostly use the traditional teaching concept (frontal): translating at home or in the class reading aloud the translation - discussion - evaluation of the translation.
\end{abstract}


Students translate various texts (non-fiction or fiction), and the choice of texts predominantly depends on the instructor. Because of the strict time framework students mostly translate several paragraphs from a text which they do not know, so that they are not familiar with the context of the passage. However, there are other teaching concepts, or innovative models which can be applied in teaching translation, like project method. At the Department for German studies at the Faculty of Philosophy of University of Novi Sad, a translation project has been organized as an extracurricular activity in which participated BA, MA and PHD students of German language and literature. They translated together (as a team) two essays from German into Serbian. In this paper the phases of the project, as well as its execution, and results have been depicted, analysed and reflected. The aim is to show the preconditions, advantages and limitations of this teaching concept as extracurricular activity at the university.

Keywords: project teaching, translation project, extracurricular activity, Karl Markus Gauss, literary translation.

\section{PROJEKTNA NASTAVA KAO NASTAVNI KONCEPT}

U zavisnosti od toga da li je nastava orijentisana na nastavnika i njegova uputstva, odnosno na učenike i njihovo individualno učenje, razlikuju se četiri osnovna nastavna koncepta: frontalna nastava, nastava orijentisana na delanje i produkciju (Handlungs- und Produktionsorientierung), projektna nastava $i$ otvorena nastava. Dok je frontalna nastava usmerena na nastavnika, u otvorenoj nastavi je nastavnik potpuno u drugom planu, a učenicima je pružena velika sloboda u samostalnom radu (Brand 2010: 123). ${ }^{1}$ Iako zahteva više vremena za pripremu od tradicionalne frontalne nastave, projektna nastava predstavlja

1 U zavisnosti od toga u kojoj meri nastavnik, odnosno učenici učestvuju i utiču na tok projekta, projektna nastava može da bude koncipirana kao otvorena nastava. Kod otvorene nastave učenje se shvata kao aktivni proces konstruisanja znanja, pri čemu se primenjuju različiti načini učenja i individualna obrada materijala. Sadržaji i teme se orijentišu prema interesovanjima učenika koji učestvuju u njihovom izboru i samostalno postavljaju ciljeve projekta, dok su rezultati projekta suštinski otvoreni. Oblici rada i metode koje se koriste $u$ otvorenoj nastavi podstiču aktiviranje učenika, omogućavaju diferencijaciju u radu i korišćenje različitih pristupa. Mesto i okruženje učenja u okviru otvorene nastave su pažljivo odabrani, okolina učenja je podsticajna i učenje je povezano sa životom. Kako bi otvorena nastava bila efektivna mora se uspostaviti dovoljna baza znanja, da se postave pravila, iniciraju i najmanji rituali i simbolička struktura nastave. Učenici bi trebalo da poseduju metodičke kompetencije, a za sporije učenike bi trebalo da se uvedu direktna uputstva. Uprkos svim pozitivnim stranama i prednostima otvorene nastave, ne treba izgubiti iz vida da bi ona ipak trebalo da bude povezana sa fazama koje vodi nastavnik (Brand 2010: 131). 
kreativni oblik nastave koji motiviše učenike i studente i omogućava im da svako od njih individualno stiče znanja brzinom koja mu odgovara. Najveći deo nastavnog procesa se uglavnom izvodi van učionice, a suština projektne nastave nije memorisanje znanja, već se ono stiče razmišljanjem, planiranjem i organizovanjem, primenom iskustva i prethodno stečenih znanja. U okviru projektne nastave učenik (student) nije objekat, već subjekat nastavnog procesa koji aktivno uči (Gombar 2011: 4). Upravo to i jeste bila namera pedagoga koji su osmislili i zagovarali ovaj koncept.

Dugogodišnja školska praksa koja je bila zasnovana na verbalizmu i dogmatizmu početkom dvadesetog veka je kod velikog broja nastavnika u Sjedinjenim Američkim Državama probudila želju i volju za inovacijama. Pravac $\mathrm{u}$ kom su se podsticale i uvodile promene u nastavni proces, između ostalog $\mathrm{i}$ „projektna metoda“ (project method), nazivao se progresivna pedagogija. Njeni najznačajniji predstavnici koji su razvili koncept projektne nastave bili su američki filozof i pedagog Džon Djui (John Dewey) i njegov naslednik Vilijam Kilpatrik (William Heard Kilpatrick) (Sanader 2014: 1-2). Predstavnici američkog pragmatizma su se nadali da ,projektna metoda“ može da doprinese humanizovanju škole i društva, jer se njome prevazilazi nastava u tradicionalnom smislu reči (Legutke 2007: 260). ${ }^{2}$ U jeku demokratizacije obrazovanja i društva nakon komunikativnog preokreta sedamdesetih godina prošlog veka (Surkamp 2010: 251) projekti su u okviru nastave stranih jezika dobili na značaju zbog povezivanja sa vanškolskom jezičkom stvarnošću, otvaranja ka svetu i usmeravanja nastave stranih jezika ka savladavanju autentičnih komunikativnih situacija (Funk, Kuhn, Skiba, Spaniel-Weise and Wicke 2014: 129). Uprkos početnom entuzijazmu, koncept projektne nastave do danas nije razrađen, niti je opšteprihvaćen.

Sadržaj i obim pojma ,projektna nastava“ su u velikoj meri ostali neodređeni, mada su dokumentovani brojni primeri u kojima se kritički istražuju mogućnosti njene primene u okviru poučavanja i učenja stranih jezika. Projektna nastava je čak dugo bila marginalna nastavna forma, ali poslednjih godina ponovo privlači sve više pažnje, prevashodno zbog toga što se u okviru ovog koncepta učenje odvaja od učionice i razvijaju se ključne kompetencije kao što su timski rad i sposobnost samostalnog rešavanja problema (Surkamp 2010: 251-252). Sve je teže zanemariti značaj ovih i drugih ključnih kompetencija za

2 Mada se začeci projektne nastave mogu naći već krajem 16. veka u Evropi (Pariz), ona je tek sedamdesetih godina prošlog veka doživela renesansu pod uticajem američkih pedagoga i to, pre svega, u severnoj i centralnoj Evropi (Knoll 1997). 
savremeno društvo u vreme globalizacije, pa u tom kontekstu i projektna nastava ponovo privlači pažnju nastavnika koji se suočavaju sa različitim nedoumicama.

Pre svega, još uvek ne postoji jedinstvena definicija ili teorija projektne nastave. U literaturi se čak pojavljuju i različiti nazivi za ovaj koncept: učenje usmereno na projekat (projektorientiertes Lernen), projektno učenje (Projektlernen), projektna nastava (Projektunterricht), projektna metoda (Projektmethode) ili projektni rad (Projektarbeit). Otuda postoje pokušaji definisanja pojma preko njegovih odlika (Funk, Kuhn, Skiba, Spaniel-Weise and Wicke 2014: 129). Iako ni u tom pogledu u literaturi ne postoji usaglašenost, postoje izvesne podudarnosti.

U zavisnosti od vremena trajanja pravi se razlika između mikroprojekata, koji uglavnom traju jedan nastavni čas, i makroprojekata, koji traju nekoliko dana ili nedelja i obuhvataju više nastavnih predmeta ili nastavnih područja (Funk, Kuhn, Skiba, Spaniel-Weise and Wicke 2014: 130). Pomenuti nastavni koncept odlikuje visok nivo aktivnog učešća učenika ili studenata u planiranju, kao i njihove samostalnosti u sprovođenju projekta. Uglavnom se primenjuju kooperativni vidovi učenja, grupni rad ili ređe rad u paru. Kao glavne odlike projektne nastave navode se: 1) usmerenost na svet učenika i njihovu životnu situaciju, 2) izbor teme, cilja i načina rešavanja zadataka u skladu sa interesovanjima učenika, 3) društveno praktična relevantnost projekata i osposobljavanje učenika da aktivno učestvuju u društvenim procesima, umesto da ih samo posmatraju, 4) usmerenost planiranja projekta na konkretan cilj koji je utvrđen na početku i čije ispunjenje predstavlja kraj projekta, 5) visok nivo samoorganizacije i samoodgovornosti učenika koji učestvuju u svim fazama projekta i sami organizuju proces učenja, 6) uključivanje što većeg broja čula, težnja ka celovitom pristupu, odnosno razmatranju predmeta iz što više perspektiva, 7) primenjivanje socijalnog učenja (kooperativno učenje), 8) usmerenost projekta na rezultat, odnosno proizvod koji se može pokazati, dostupan je javnosti i može se javno vrednovati i kritikovati, 9) interdisciplinarni pristup, proučavanje odabranih sadržaja iz različitih perspektiva (Brand 2010: 127-128). Kao ključne reči projektne nastave izdvajaju se povezanost sa svakodnevicom i stvarnošću, interkulturalnost, usmerenost na proces, rezultat i interakciju, učenička autonomija i otvaranje prema svetu. Osim na konkretnom „rezultatu“ težište projektne nastave je i na razvijanju projektne kompetencije, kao i sposobnosti za samostalno učenje i preuzimanje odgovornosti za sopstveni proces učenja. Uloga nastavnika $\mathrm{u}$ tom procesu jeste da učenicima stavi na raspolaganje nastavni materijal i nastavna sredstva, da posmatra proces, da eventualno savetuje i usmerava učenike prilikom rešavanja problema. U određenim vremenskim razmacima nastavnici mogu da sastavljaju izveštaje o 
trenutnom statusu projekta, odnosno o dosadašnjim rezultatima, čime se učenici podstiču da jedni drugima pomažu i daju savete o daljem nastavku rada, odnosno da autonomno, samostalno uče (Funk, Kuhn, Skiba, Spaniel-Weise and Wicke 2014: 130-131, 150-152).

Budući da je reč o procesu, on se odvija u nekoliko faza. Međutim, ne postoji jedan jedinstveni model projektne nastave ili neki koji se izdvojio i postao univerzalno prihvaćen (Gombar 2011: 4). U literaturi se uglavnom pominju sledeći koraci. Kao prvi korak se navodi ispitivanje i otkrivanje potreba i interesovanja učenika, tema i predmeta koji bi mogli da dođu u obzir, kao i mogućnosti njihovog povezivanja. $U$ drugoj fazi se donosi odluka o ciljevima projekta, po mogućnosti zajednički, u grupi, tako da svi učestvuju. Na taj način se formira svest o zajedničkom cilju, kao i mogućim podciljevima. Sledeći korak je planiranje vremenskog okvira i očekivanog rezultata projekta, pri čemu se određuju samo grubi koraci, odnosno sadržinske smernice i osnovne ideje, kao i načelna pitanja na koja treba dati odgovor. Planiranje bi, takođe, trebalo da se sprovede kooperativno, u grupi. U fazi sprovođenja projekta učenici treba da samostalno skupljaju materijal, pripremaju projekat, ostvaruju i prezentuju rezultate, dok nastavnik treba samo da ih savetuje. Konačni rezultati projekta se predstavljaju u plenumu, o njima se zajednički diskutuje, kritički se razmatraju i predstavljaju se javnosti (barem školskoj). Na kraju sledi završna refleksija rezultata, a ukoliko ima potrebe, donose se zajedničke odluke, i naglašava se inovativni doprinos ostvaren zajedničkim radom u okviru projekta (Brand 128-129).

Suštinska prednost projektne nastave jeste što učenici (studenti) kroz izradu projekata stiču nova znanja, ali i razvijaju sposobnosti kao što su veština planiranja, organizovanja i sprovođenja istraživanja, zaključivanja i donošenja odluka, pisanog i usmenog izražavanja, socijalne i praktične veštine (Gombar 2011: 4). Drugim rečima, u okviru projektne nastave stiču se i razvijaju specifične (predmetne), ali i opšte (ključne) kompetencije, u podsticajnoj okolini, i uz mogućnost samostalnog organizovanja sopstvenog rada.

Iako se projektna nastava koristi u školama u Srbiji, na primer, u nastavi društvenih predmeta u nižim razredima (Gombar 2011), ili nastavi tehničkog i informatike (Sanader 2014, Šiki and Novković 2012), kao inovativni model još uvek nije u potpunosti zaživela i postala sastavni deo školske i univerzitetske nastavne prakse. Budući da ni nastavnici ni studenti nisu dobro upoznati sa ovim konceptom, projektna nastava je na Odseku za germanistiku prvo primenjena kao vannastavna aktivnost na Filozofskom fakultetu u Novom Sadu, s mogućnošću njenog uvođenja u (van)nastavnu praksu. 


\section{PREVODILAČKI PROJEKAT NA ODSEKU ZA GERMANISTIKU}

Projekat „Prevođenje tekstova Karla Markusa Gausa o Dunavu“ deo je međunarodnog projekta pod nazivom $\mathrm{Na}$ Dunavu: evropski književni projekat (An der Donau: Ein europäisches Literaturprojekt). Nastao je u okviru saradnje Odseka za germanistiku Filozofskog fakulteta u Novom Sadu sa Institutom za podunavskošvapsku istoriju i kulturu u Tibingenu (Institut für donauschwäbische Geschichte und Landeskunde, Tübingen), a u dogovoru sa koordinatorkom saradnje, dr Olivijom Spiridon (Olivia Spiridon).

$\mathrm{Na}$ projektu je učestvovalo deset studentkinja i dvoje studenata sa osnovnih (Andrea Došenović, Ivana Glintić, Zoran Mihajlović, Jelena Mimić, Jelena Stankov), master (Biljana Kovač, Maja Stojanović, Milica Vrgović) i doktorskih (Ivana Marinkov, Ana Mitrevski, Žolt Papišta, Mirjana Zarifović) studija. U projekat je bio uključen i austrijski lektor, Paul Gruber, kao konsultant za nemački jezik i austrijsku kulturu. Projektom je rukovodila prof. dr Nikolina Zobenica.

Prve pripreme za projekat započele su u septembru 2015, a projekat je završen u martu 2016. godine. Komunikacija je prvo uspostavljena preko elektronske pošte, a zatim je nastavljena preko zajedničke, zatvorene grupe formirane na društvenoj mreži (fejsbuk). Održana su i četiri susreta $u$ seminarskoj biblioteci Odseka za germanistiku, kao i prezentacija projekta u okviru manifestacije Prevodilački dani na Filozofskom fakultetu u Novom Sadu (24. mart 2016). Na kraju je sprovedena evaluacija u okviru koje su studenti iskazali svoje mišljenje o različitim aspektima projekta.

\subsection{Priprema i planiranje projekta}

U okviru pripreme za projekat paralelno su tekli dogovori sa koordinatorkom projekta $\mathrm{u}$ Tibingenu i sa studentima. Izbor tekstova je ograničen samom temom projekta, te je jedini uslov bio da se prevode tekstovi o reci Dunav. Trebalo je da se studenti odluče između drame klasičnog austrijskog pisca Franca Grilparcera (Franz Grillparzer), Sreća i kraj kralja Otokara (König Ottokars Glück und Ende) i dva eseja savremenog pisca Karla Markusa Gausa, Učenje Dunava (Die Lehre der Donau) i Kako Dunav teče (Die Donau hinab). Studenti su se glasanjem na društvenoj mreži zajednički opredelili za prevođenje Gausovih tekstova, dr Spiridon je stupila u kontakt s piscem i dobila njegovu saglasnost, kao i uputstva za regulisanje autorskih prava.

Osim toga, bilo je neophodno da se utvrdi institucionalni okvir projekta, te je dobijena saglasnost Odseka za germanistiku i Nastavno-naučnog veća 
Filozofskog fakulteta. S obzirom na to da je Pravilnikom o vrednovanju vannastavnih aktivnosti studenata Filozofskog fakulteta Univerziteta u Novom Sadu (2014: čl. 2, stav 3) obuhvaćeno i „učešće u pripremanju i realizaciji naučnih i stručnih projekata [...] u organizaciji organa i organizacionih jedinica (odseka, centara, Biblioteke) Fakulteta i Univerziteta (letnjih škola, radionica i dr.)“, odlučeno je da se studentima na kraju izda potvrda o učešću na projektu sa odgovarajućim brojem ESPB, kako bi im se priznao i vrednovao kao vannastavna aktivnost.

„Broj ostvarenih ESPB bodova utvrđuje se u skladu sa sadržajem, ishodima i radnim opterećenjem studenata $u$ realizaciji specifične vannastavne aktivnosti, uz primenu jedinstvene metodologije za izračunavanje opterećenja, odnosno, na osnovu ukupnog angažovanja studenta: ukupnog broja časova aktivnog rada i ukupnog broja sati utrošenih na pripremu za realizaciju aktivnosti.“ (čl. 12, stav 2)

U tu svrhu je izrađena tabela u koju je trebalo unositi sve aktivnosti tokom projekta, kao i broj utrošenih sati za svaku od tih aktivnosti. Tabela je stavljena na raspolaganje svim učesnicima projekta preko društvene mreže.

\begin{tabular}{|l|l|}
\hline AKTIVNOST & UTROŠEN BROJ SATI \\
\hline Čitanje eseja & \\
\hline Prevođenje eseja & \\
\hline Radionice & \\
\hline Konsultacije & \\
\hline$\ldots \ldots$. & \\
\hline$\ldots \ldots$. & \\
\hline UKUPNO & \\
\hline
\end{tabular}

Tabela 1: Broj utrošenih sati na projektu

Nakon toga, usledio je prvi susret na kojem su dodeljeni zadaci za prevođenje. Oba teksta su prema broju učesnika podeljena na manje celine i svako je dobio otprilike isti segment teksta za prevođenje. Utvrđen je tempo prevođenja i rad na verzijama: prva verzija je bila dogovorena za 15. decembar, druga za 15. februar, a treća i konačna verzija je trebalo da bude gotova u martu, kad bi se na radionici u okviru Prevodilačkih dana, organizovanih na Filozofskom fakultetu u Novom Sadu (23-24. mart 2016) prezentovao projekat. Raspodela 
zadataka, kao i ostale odluke sa tog susreta postavljene su u formi zapisnika na društvenu mrežu i na taj način su bile dostupne svim članovima grupe. Nakon ovog dogovora studentima je prepušteno da samostalno organizuju kada i kako će prevoditi odgovarajuće delove teksta.

\subsection{Realizacija projekta}

Studenti su narednih meseci samostalno (individualni rad) prevodili tekstove. Prvi susret, planiran za decembar, odložen je za januar, kada se razgovaralo o nedoumicama na koje su naišli prilikom prevođenja teksta. Tom prilikom su učesnicima projekta stajali na raspolaganju jednojezični i dvojezični rečnici, internet izvori, znanja koleginica i kolega (kooperativno učenje), a bio je prisutan i strani lektor, koji je u velikkoj meri olakšao rešavanje pojedinih nedoumica, kako jezičkih tako i kulturoloških. Kao maternji govornik lektor je, na primer, razjasnio značenje nemačke složenice „Zwangsvorstellung“, koja bi razložena na sastavne delove „Zwang“ i „Vorstellung“, u značenju „prisila, nametanje“ i „predstava“, moglo da znači ,prisilna, nametnuta predstava“. Međutim, lektor je skrenuo pažnju na značenjsku komponentu koja nije sadržana u ovim dvema rečima i koja je na prvi pogled skrivena („opsesivnost“). Pored toga, s obzirom na to da je sam autor Austrijanac i da je dobrim delom $u$ njegovim esejima reč o istoriji Austrougarske monarhije, maternji govornik je mogao da razreši određene kulturološko-istorijski uslovljene nedoumice kao što je „Ostmark“. Budući da je složenica sastavljena od reči „Ost" u značenju ,istok“ i „Mark“, reč koja je u srednjem veku označavala „graničnu teritoriju“, značenje ove složenice bi bilo ,istočna teritorija“. Međutim, lektor je skrenuo pažnju da je „Ostmark“ bio naziv za Austriju u vreme nacionalsocijalizma, nakon njenog pripajanja Trećem rajhu, što ostalim učesnicima projekta nije bilo poznato.

Prilikom rešavanja nedoumica došlo je do izražaja u kojoj meri je tokom prevođenja neophodno primenjivati istraživačku metodu. ${ }^{3}$ Studenti su morali da samostalno u rečnicima i na internetu (različiti izvori znanja) potraže razjašnjenje brojnih pojmova (intelektualni rad) i da nađu odgovarajuće ekvivalente (stvaralački rad). Nastavnik pritom nije bio prisutan, ali je u fazi

3 Istraživačka metoda se definiše kao individualni, grupni rad, rad u tandemu ili samostalno intelektualni ili intelektualno-praktični rad učenika ili studenta na različitim izvorima znanja. Nastavnik pritom kontroliše i usmerava rad učenika ili studenta ka traganju za odgovorima na neko pitanje ili za rešenjem nekog zadatka ili problema. Budući da se ovom metodom potencira samostalni i stvaralački rad učenika ili studenta, nastavnik je sve manje prenosilac gotovih znanja. Istraživački rad je kompleksna metoda koja se sastoji iz koraka planiranja, prikupljanja činjenica, obrade, provere i saopštenja rezultata istraživanja (Jukić 2005: 46-47). 
rešavanja nedoumica učestvovao zajedno sa ostalim članovima grupe. Povod za istraživački rad dale su reči kao što je, na primer, „Heidentor“, složenica koja se sastoji iz reči „Heiden“, u značenju „pagani, nevernici“ i „Tor“, u značenju „vrata, kapija“. Moguće je nekoliko kombinacija značenja, kao što su, na primer, „paganska vrata“, „paganska kapija“ ili „,nevernička vrata“, odnosno „,nevernička kapija“, „vrata (kapija) nevernika“ i sl. S obzirom na to da je reč o građevini u Austriji, bilo je važno saznati da li je sagrađena u vreme Rimljana ili Turaka, jer to usmerava izbor ekvivalenata. Pošto je reč o ulazu u rimski Karnuntum sagrađenom u 4. veku, nametnuo se prevod ,paganska vrata“. Sličan slučaj je i sa rečju „Götterfels“ (doslovno „stena bogova“) u sklopu Belogradčika u Bugarskoj, za koju nije bilo sasvim jasno da li je reč o geografskom ili kulturološko-istorijskom nazivu ili samo o poetskom izrazu. Na osnovu provere različitih geografskih i turističkih izvora zaključeno je da je reč o poetskom izrazu i složenica je prevedena kao „stene dotaknute nebom“.

$\mathrm{U}$ prethodnom primeru se vidi da kreativnost u prevođenju igra veoma značajnu ulogu, ${ }^{4}$ kao što je bilo i u nizu drugih slučajeva. Na primer, dve nemačke reči „furchtbar“ i „fruchtbar“ povezane su rimom i aliteracijom, što u prevodu ne može da se zadrži, budući da njihovi ekvivalenti „strašno, užasno“ i „plodonosno, plodotvorno“ nisu povezani aliteracijom, a čak i kod povezivanja reči „strašno“ i „plodonosno“ rima nije izražena kao u originalu. U kreativnoj igri s jezikom odabrana je kombinacija „strahotvorno“ i „plodotvorno“, kako bi se naglasila povezanost dva lica, dva efekta jedne pojave, pri čemu je ova kombinacija reči prikladna, a ipak nova.

Studentima se tokom prevođenja nameću ovakvi zadaci koji predstavljaju različite problemske situacije. Polazišta problemske situacije su neka nepoznata znanja i nepoznati načini rešavanja problema, odnosno postoji neka saznajna potreba koja budi misaonu aktivnost i podstiče intelektualne mogućnosti, stvaralačke sposobnosti i prethodno iskustvo učenika (studenata). Problemska nastava obezbeđuje povećanje obima znanja, umenja i navika učenika ili studenata, produbljuje njihova postojeća znanja, obezbeđuje viši nivo njihovih saznajnih potreba, saznajne samostalnosti i stvaralačkih sposobnosti. Za problem, odnosno zadatak, uvek postoji različiti broj mogućih rešenja, a razlika između

4 Kreativnost pri tome ne treba shvatati kao mistični događaj, već je kreativno prevođenje u određenoj meri transparentno, može se poučavati i učiti, jer kreativni put vodi preko mentalnih predstava, objašnjava se pomoću kognitivnih modela, scenskih predstava i izbora prototipskih elemenata (suštinskih elemenata značenja) koje treba preneti prilikom prevođenja. Da bi se neki proizvod mogao nazvati kreativnim, potrebno je da ga odlikuju novina i prikladnost (Kußmaul 2010: 121-132), što su i odlike kreativnog prevoda. 
problema i „običnog“ zadatka jeste komponenta nepoznatog. Učenici (studenti) pri tome dobijaju samo osnovne informacije koje međusobno kombinuju i dolaze do novih rešenja za koje je potreban stvaralački pristup i iskustvo. Rešenjem zadatog problema stiču se nova i produbljuju već postojeća znanja, a razvijaju se i umne sposobnosti (Šiki and Novković 2012: 3). Prilikom prevođenja stalno se pojavljuju novi problemi koji zahtevaju kreativna rešenja, a studenti pri tome treba da pomeraju granice svog dosadašnjeg znanja i iskustva.

Kad je reč o postupcima rešavanja prevodilačkih problema, treba uzeti u obzir nekoliko aspekata književnog prevođenja sa kojima su se studenti suočili tokom prevođenja i koji su razmatrani na zajedničkim susretima. Tokom rada na projektu istaknuto je da broj značenja leksičkih jedinica (semantika) nije ograničen rečničkim odrednicama, da se značenje menja u zavisnosti od konteksta i upotrebe leksičkih jedinica (pragmatika), kao i da u književnom tekstu treba voditi računa o kontekstu i o jezičkom izrazu (stilistika). U suštini je reč o semantičkoj, pragmatičkoj i stilističkoj adekvatnosti koje pominje Gončarenko u svom radu o tipologiji pesničkih prevoda (Gončarenko 1989: 326-330) i tih adekvatnosti su studenti postali svesni prilikom rada na projektu.

Upravo u slučaju kada se rešenje ne može naći (odmah), odnosno kad su neki izrazi prividno neprevodivi, često se kao najjednostavnijem i najlakšem rešenju pribegava izostavljanjima ili objašnjenjima u zagradama ili fusnotama. Međutim, iako to jesu legitimne tehnike u prevođenju, one bi trebalo da budu korišćene samo u slučajevima kada je to zaista neophodno i kad se pri tome ne izneverava original. Eko (2011: 108), na primer, izostavljanja u pojedinim slučajevima smatra i prihvatljivim gubicima, ali korišćenje fusnota vidi kao poslednje rešenje, odnosno priznanje prevodiočevog poraza, te se napomene prilikom prevođenja Gausovih eseja nisu koristile.

U pojedinim slučajevima prevod nije zvučao adekvatno na srpskom jeziku, ali se prilikom provere nemačkog teksta ispostavljalo da nije reč o greški prevodioca, već o vernom prenošenju tekstu originala. U takvim situacijama prevodilac dolazi u iskušenje da ,popravlja“ izvorni tekst, odnosno da sintaksu ili leksiku autora prilagodi sopstvenom osećaju za jezik prevoda, pri čemu se suštinski ne prenosi stil autora, odnosno dolazi do njegove ,izdaje“. Time se postavlja večita prevodilačka dilema - vernost ili sloboda prilikom prevođenja? Proučavajući prevodilačke univerzalije, Česterman (Chesterman 2010: 39) je došao do zaključka da prevod ima nedostatke ukoliko je previše neprirodan ili se previše razlikuje od izvornog teksta, te on greške koje nastaju prilikom prevođenja svrstava u dve glavne grupe: one koje ne prenose značenje ili stil izvornika i one koje krše gramatičke ili stilističke norme ciljnog jezika. Iz tog razloga bi prevod trebalo da teži prirodnosti i tačnosti u jednakoj meri i ne bi 
trebalo da izneverava nijedan od ova dva zahteva. Time su se rukovodili i studenti prilikom prevođenja Gausovih tekstova, u nastojanju da tekst bude veran originalu, ali da ipak zvuči prirodno na srpskom jeziku. Međutim, konačna odluka o pravom ili prihvatljivom izrazu treba da bude prevodiočeva, jer on najbolje poznaje originalni tekst i tekst prevoda, i zna zašto je određeno rešenje odabrao kao bolje od drugog.

Prevođenje je proces tokom kojeg se stalno donosi čitav niz odluka, a prevodioci pri tome treba uvek da znaju šta rade i zašto to rade. Prevodilačka praksa zahteva od prevodilaca sposobnost da objasne svoje prevodilačke odluke, ali i da shvate zašto su ih doneli, jer na taj način skupljaju iskustvo i razvijaju svoju stručnost. Svaka prevodilačka odluka zahteva prilagođavanje već stečenog znanja, a svesno odlučivanje, povezano sa sposobnošću da se objasne razlozi donošenja određene odluke predstavljaju postupke koji odlikuju prave stručnjake (Kadrić, Kaindl and Cooke 2012: 149-150). Nijedna odluka ne treba da bude donesena ishitreno i proizvoljno, tako da su studenti svoja rešenja ili predloge obrazlagali argumentima koji ponekada jesu, ponekada nisu bili ubedljivi i prihvatljivi.

Nedoumice koje nisu rešene na zajedničkom sastanku, uz upotrebu rečnika i interneta, u saradnji sa studentima, nastavnikom i lektorom, i za koje se pokazalo da je potrebno dodatno istraživanje, ostale su otvorene i rešavane su samostalno kod kuće i, ukoliko je bilo potrebe, uz konsultacije sa grupom. Na taj način su učesnici projekta podelili rezultate sopstvenih istraživanja (kooperativno učenje), a prevodioci su sami odabrali ona koja su smatrali najadekvatnijima (samostalno odlučivanje).

U sledećem koraku su rešenja za nedoumice integrisana $u$ tekst prevoda i ta verzija prevoda je poslata koordinatoru projekta elektronskim putem. Profesorka je objedinila prevode i stavila ih svima na uvid. Prilikom sledeća dva susreta urađeno je redigovanje prevoda. Tekst je čitan naglas, svi prisutni su obeležavali sve za šta su smatrali da ,škripi“ u prevodu, odnosno da je nejasno ili neadekvatno ili prepoznato kao gramatička ili pravopisna greška. Nakon toga, razgovaralo se o problematičnim delovima prevoda, predložena su bolja rešenja ili ispravke. Ono što je ostalo nerazjašnjeno ponovo je bilo predmet diskusije u grupi.

Nakon što su ispravke unesene, studenti su profesorki poslali treću verziju svojih prevoda koje je ona ponovo objedinila, a zatim je redigovala ceo prevod i stavila svoje ispravke na uvid u grupu. Nakon nekoliko intervencija studenata, tekst je ponovo korigovan i poslat na lektorisanje profesorki srpskog jezika. Lektorisana verzija je takođe stavljena na uvid studentima u grupi i urađeno je još nekoliko manjih intervencija. Uz saglasnost većine studenata (neki se nisu 
oglasili), konačna verzija prevoda je, zajedno sa imenima prevodilaca, poslata koleginici Spiridon, i oni su objavljeni na internet stranici projekta Na Dunavu: evropski književni projekat (www.danubylon.de).

\subsection{Rezultati projekta}

Cilj projekta je bio da se prevedu dva eseja, da se ti prevodi objave i da budu dostupni javnosti. Projekat je prezentovan na Prevodilačkim danima Filozofskog fakulteta, pri čemu je prof. dr N. Zobenica prvo upoznala prisutne koleginice i kolege sa nastankom projekta, a nekoliko studentkinja je predstavilo različite aspekte projekta. Govorile su o autoru i njegovom delu (M. Stojanović), o razlikama između stručnog i književnog prevođenja (B. Kovač), o timskom prevođenju (J. Mimić), fazama prevođenja (A. Došenović) i o nedoumicama prilikom prevođenja (J. Stankov), kao i o tome šta su naučili tokom projekta (I. Marinkov). Moderaciju prezentacije projekta i diskusije nakon projekta preuzela je studentkinja I. Glintić.

Studenti su nakon toga predali tabele sa spiskom aktivnosti i brojem utrošenih sati na projektu, pri čemu su primetne znatne razlike kod učesnika projekta koji su bili prisutni na svakom susretu i onih koji su bili prisutni samo na jednom ili dva susreta. Isto tako, imenovanje i navođenje aktivnosti nije bilo ujednačeno, a mnogi su izostavili vreme utrošeno na pripremu i održavanje prezentacije, što nije u velikoj meri uticalo na konačan rezultat.

\begin{tabular}{|c|c|c|c|c|c|c|c|c|c|c|c|c|c|c|}
\hline \multirow{2}{*}{ AKTIVNOST } & \multicolumn{14}{|c|}{ UTROŠEN BROJ SATI PO UČESNIKU } \\
\hline & 1 & 2 & 3 & 4 & 5 & 6 & 7 & 8 & 9 & 10 & 11 & 12 & & A \\
\hline čitanje eseja & 03,50 & 03,00 & 00,50 & 01,00 & 01,50 & 01,00 & 04,00 & 04,50 & 03,00 & 03,00 & 00,33 & 04,00 & & 02,44 \\
\hline Prevođenje & 10,00 & 04,00 & 12,00 & 10,00 & 16,00 & 05,00 & 16,00 & 14,00 & 10,00 & 12,00 & 12,00 & 10,00 & & 10,92 \\
\hline Radionice & 17,00 & 04,00 & 10,75 & 12,50 & 17,25 & 17,00 & 10,75 & 17,75 & 03,00 & 00,66 & 15,66 & 06,00 & & 11,03 \\
\hline Konsultacije & - & - & 00,50 & - & 01,33 & 01,00 & - & - & - & 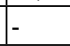 & - & 01,00 & & 00,32 \\
\hline FB grupa & - & - & 01,00 & 00,25 & - & - & - & - & & - & - & - & & 00,13 \\
\hline Redigovanje & 00,50 & 04,00 & 03,00 & 03,00 & 05,50 & 05,00 & 02,00 & 02,00 & 04,00 & 04,00 & - & - & & 03,30 \\
\hline $\begin{array}{l}\text { Kontrolisanje } \\
\text { sopstvenog } \\
\text { prevoda }\end{array}$ & 03,00 & - & - & - & - & 01,00 & + & - & - & - & - & - & & 00.40 \\
\hline $\begin{array}{l}\text { Planiranje } \\
\text { prezentacije }\end{array}$ & 01,00 & - & - & 00,25 & - & - & $\left.\right|^{-}$ & - & - & - & - & - & & 00,13 \\
\hline $\begin{array}{l}\text { Učešće na } \\
\text { prezentaciji }\end{array}$ & 01,00 & - & - & - & - & - & - & - & - & - & - & - & & 00,10 \\
\hline Predgovor & - & - & $5^{-}$ & 02,00 & - & $b^{-}$ & ]$^{-}$ & - & - & - & - & - & & 00,20 \\
\hline UKUPNO & 36,00 & 15,00 & 27,75 & 29,00 & 41,58 & 30,00 & 32,75 & 38,25 & 20,00 & 19,66 & 28,00 & 21,00 & $28,25 \mid$ & 28,97 \\
\hline
\end{tabular}

Tabela 2: Broj utrošenih sati po učesniku 
Broj ESPB bodova je utvrđen prema metodologiji preporučenoj u Vodiču kroz ESPB (2009), na osnovu srednje vrednosti izračunatog broja sati za svakog pojedinog učesnika. Budući da srednja vrednost iznosi oko 29 sati, za ovu vannastavnu aktivnost studenti dobijaju 1 ESPB, što odgovara prosečnom opterećenju od 25 do 30 sati.

U okviru evaluacije studenti su se izjasnili u vezi sa svojom motivacijom pre, za vreme i nakon projekta. Motivacija je uglavnom intrinzična: većina studenata se priključila projektu zato što vole prevođenje $\left(A S=4,83^{5}\right)$, manje zbog književnosti $(\mathrm{AS}=4,33)$ i književnog prevođenja (AS=3,75). Studenti su uglavnom želeli da se oprobaju u književnom prevođenju i da ga vežbaju $(\mathrm{AS}=4,75)$. Skoro nikakvu ulogu nisu igrali spoljašnji faktori kao što je učešće drugih koleginica i kolega (AS=1,93), sertifikat i ESPB bodovi (AS=2) ili pisac K.M. Gaus $(A S=1,33)$, dok je mogućnost objavljivanja prevoda na internet stranici projekta bila nešto bolji motivator $(\mathrm{AS}=2,83)$. Motivacija je varirala tokom projekta: bila je prilično visoka na početku $(\mathrm{AS}=4,5)$, da bi opala tokom projekta $(\mathrm{AS}=3,92)$ i na kraju ponovo porasla, ali ipak ne do početne vrednosti $(\mathrm{AS}=4,33)$. Projekat uglavnom nije uticao na želju studenata da se bave prevođenjem $(\mathrm{AS}=3,00)$, većina njih želi da se bavi prevođenjem nakon ovog projekta $(\mathrm{AS}=4,5)$, mada manje književnim prevođenjem $(\mathrm{AS}=3,85)$. Sami studenti bi uglavnom želeli da ponovo učestvuju na ovakvom projektu sledeće godine (AS=4,17), a ako oni ne budu bili u mogućnosti, svakako bi ga preporučili drugima (AS=4,83).

Kad je reč o komunikaciji preko društvene mreže, tokom projekta se pokazalo da ona ima brojne prednosti. Pre svega, takva komunikacija omogućava svim učesnicima projekta direktan pristup svim podacima, dokumentima, kao i nesmetanu razmenu podataka i mišljenja, mogućnost postavljanja pitanja i davanja odgovora, kao i vođenja diskusije. Na taj način se osiguravaju dostupnost i transparentnost. Isto tako, pruža se mogućnost zajedničkog donošenja odluka putem glasanja i odluke većine, čime se neguju demokratičnost i tolerancija. Ograničenja ovakvog načina komunikacije jesu pre svega što nisu svi učesnici projekta uvek dostupni ili nisu dostupni u isto vreme, a ako i jesu, mogu i ne moraju da aktivno učestvuju u radu grupe i imaju priliku da izbegavaju ili odlažu komunikaciju i učešće, što se loše odražava na saradnju u grupi, kao i njenu kohezivnost i dinamiku.

5 U evaluaciji je korišćena petostepena Likertova skala, pri čemu je 1 - potpuno se ne slažem, 2 - uglavnom se ne slažem, 3 - i slažem se i ne slažem se, 4 - uglavnom se slažem, 5 - potpuno se slažem. U radu se iznose prosečne vrednosti (AS) za svaku od navedenih izjava (stavova). 
Učesnici projekta su smatrali da je komunikacija tokom projekta bila dobra $(A S=4,5)$ i uglavnom im se dopadala komunikacija preko društvene mreže $(A S=4,17)$. Imali su osećaj da mogu da slobodno iskažu svoje mišljenje $(\mathrm{AS}=4,83)$ i da samostalno odlučuju $(\mathrm{AS}=4,65)$. Saradnja sa koleginicama i kolegama je ocenjena kao prilično prijatna $(\mathrm{AS}=4,58)$, ali efikasnost je nešto slabije ocenjena $(\mathrm{AS}=4,00)$.

Kad je reč o stečenim znanjima i veštinama, studenti su uglavnom mišljenja da su mnogo naučili $(A S=4,58)$ i pre svega su visoko ocenili poboljšanje svoje veštine prevođenja $(\mathrm{AS}=4,67)$ i stečena znanja iz kulture $(\mathrm{AS}=4,67)$, zatim znanja iz vokabulara nemačkog i srpskog jezika $(\mathrm{AS}=4,5)$, a nešto manje i gramatike ( $\mathrm{AS}=4,08)$.

$\mathrm{Na}$ kraju, od ishoda formulisanih u Pravilniku o vannastavnim aktivnostima (2014: čl. 11, st. 3-8), studenti su ocenili da su na projektu najviše usavršavali i razvijali lične i profesionalne potencijale, veštine istraživanja, argumentovanog raspravljanja i donošenja odluka. Svi ostali ishodi su takođe ostvareni u velikoj meri, pri čemu je najniža prosečna vrednost pripisana primeni znanja i veština stečenih tokom studija $(\mathrm{AS}=4,00)$.

\begin{tabular}{|l|c|}
\hline ISHODI & AS \\
\hline $\begin{array}{l}\text { Kontinuirano se stručno usavršava i razvija i unapređuje lične iprofesionalne } \\
\text { potencijale. }\end{array}$ & 4,75 \\
\hline $\begin{array}{l}\text { Prikuplja i kritički analizira relevantne podatke, argumentovano raspravlja } \\
\text { i odlučuje o društvenim, naučnim ili etičkim pitanjima. }\end{array}$ & 4,58 \\
\hline $\begin{array}{l}\text { Profesionalno i korektno obaveštava stručnu i širu javnost o radu i } \\
\text { rezultatima rada organa ili tela Fakulteta ili Univerziteta }\end{array}$ & 4,33 \\
\hline $\begin{array}{l}\text { Kritički preispituje, unapređuje i promoviše kulturu osiguranja kvaliteta u } \\
\text { visokom obrazovanju. }\end{array}$ & 4,33 \\
\hline $\begin{array}{l}\text { Konstruktivno sarađuje sa drugima, ostvaruje kvalitetnu komunikaciju i } \\
\text { efikasno doprinosi timskom radu. }\end{array}$ & 4,17 \\
\hline $\begin{array}{l}\text { Primenjuje znanja i veštine stečene tokom studija prilikom rešavanja } \\
\text { problema različitog stepena složenosti na način koji ukazuje na } \\
\text { profesionalan i etičan pristup poslu ili zvanju. }\end{array}$ & 4,00 \\
\hline
\end{tabular}

Tabela 3: Ishodi projekta

S obzirom na to da su studenti procenili da su ishodi predviđeni Pravilnikom ostvareni, izrađene su potvrde za učešće na projektu koji ima osnova da bude priznat kao vannastavna aktivnost i upisan u Dodatak diplome. 


\section{ZAKLJUČAK}

Prevodilački projekat „Prevođenje tekstova Karla Markusa Gausa o Dunavu“" sproveden je u nekoliko faza u skladu sa principima projektne nastave: 1) izbor teme, 2) odluka o cilju, 3) planiranje, 4) sprovođenje, 5) refleksija i evaluacija rezultata projekta. $\mathrm{S}$ obzirom na to da izbor teme nije bio sasvim slobodan i usmeren na interesovanja studenata, ne može se reći da je reč o otvorenoj nastavi.

Prevođenje u okviru projektne nastave daje priliku za primenu različitih oblika rada (individualni, rad u paru, rad u grupi, plenum), kao i za inovativne modele i metode poput problemske nastave i istraživačkog rada, kao i stvaralačkog rešavanja problema. Glavna prednost opisanog nastavnog koncepta jeste visok stepen samostalnosti i autonomnosti studenata, njihovog učešća $u$ odlučivanju o sadržajima, tempu i načinu rada, kao i osećanja odgovornosti za sopstveni rad, ali i za rad cele grupe. Razvijaju se opšte kompetencije istraživanja, argumentovanja, upravljanja vremenom, timskog rada i prezentovanja.

S obzirom na to da je reč o vannastavnoj, dakle fakultativnoj aktivnosti, intrinzična motivacija je bila glavni pokretač svih aktivnosti. Dok je ona kod nekih učesnika projekta bila konstantno visoka, kod drugih je varirala tokom projekta i uticala je na kvalitet rada. Iz tog razloga je preporučljivo praviti selekciju učesnika ovakvih projekata putem motivacionog pisma i probnog prevoda, jer na taj način se osigurava kvalitetniji rad u okviru projekta.

Sloboda i samostalnost učenika (studenata) u radu na ovakvim projektima je velika prednost, ali ona zahteva zrelost učesnika, njihovu spremnost za rad i za preuzimanje pune odgovornosti ne samo za rezultate rada, već i odgovornosti prema ostalim učesnicima projekta. Ukoliko ne postoje radne navike i odgovoran odnos prema radu i izraženo osećanje kolegijalnosti, sloboda može da donese više štete nego koristi. Međutim, saradnja sa mladim ljudima koji zaista jesu spremni da odgovorno preuzmu i ispunjavaju svoje obaveze u okviru projektne nastave može biti vrlo inspirativno i plodotvorno iskustvo za sve učesnike.

\section{LITERATURA}

Brand, T. (2010). Deutsch unterrichten: Einführung in die Planung, Durchführung und Auswertung in den Sekundarstufen. Seelze-Velber: KallmeyerKlett.

Chesterman, A. (2010). "Why study translation universals?". Acta Translatologica Helsingiensia 1: 38-48. 
Eko, U. (2011). Kazati gotovo istu stvar. Beograd: Paideia.

Ende, K., Grotjahn, R., Kleppin, K. and I. Mohr (2013). Curriculare Vorgaben und Unterrichtsplanung. München: Goethe-Institut.

Funk, H., Kuhn, Ch., Skiba, D., Spaniel-Weise, D. and R. E. Wicke (2014). Aufgaben, Übungen, Interaktion. München: Goethe-Institut.

Gombar, M. (2011). "Primena projektne nastave u izučavanju društvenih sadržaja u nižim razredima osnovne škole“. Norma 16/1: 103-114.

Gončarenko, S. (1989). "Tipologija pesničkih prevoda i književna kritika“. Prev. sa ruskog Milica Slavković. Mostovi 80: 326-330.

Jukić, S. (2005). Didaktičko-metodički fragmenti: izabrani radovi. Vršac: Viša škola za obrazovanje vaspitača.

Kadrić, M., Kaindl, K. and M. Cooke (2012). Translatorische Methodik. Wien: Facultas.

Kußmaul, P. (2010). Verstehen und Übersetzen. Tübingen: Narr Verlag.

Knoll, M. (1997). "The Project Method: Its Vocational Education Origin and International Development". Journal of Industrial Teacher Education 34 (3). Pristupljeno 31. 3. 2016. URL: <http://scholar.lib.vt.edu/ejournals/ $\mathrm{JITE} / \mathrm{v} 34 \mathrm{n} 3 / \mathrm{Knoll} . \mathrm{html}>$.

Legutke, M. K. (2009). "Projektunterricht", in Handbuch Fremdsprachenunterricht, hrsg. v. K-R. Bausch, H. Christ and H-J. Krumm (Tübingen and Basel: A. Francke Verlag): 259-263.

Pravilnik o vrednovanju vannastavnih aktivnosti Filozofskog fakulteta Univerziteta u Novom Sadu (2014). Novi Sad: Filozofski fakultet. Pristupljeno 1. 2. 2016. URL: <http://www.ff.uns.ac.rs/fakultet/pravilnici/Pravilnik $\% 20$ o\%20vrednovanju\%20vannastavnih\%20aktivnosti\%202014.pdf $>$.

Sanader, M. and G. (2014). "Projektna nastava tehničkog i informatičkog obrazovanja“, u Tehnika i informatika u obrazovanju: 5. Konferencija sa međunarodnim učešćem (Čačak: Fakultet tehničkih nauka): 1-6.

Surkamp, C. (2010). Metzler Lexikon Fremdsprachendidaktik. Stuttgart and Weimar: Verlag J. B. Metzler.

Šiki, A. and A. Novković (2012). "IKT u kontekstu razvoja problemskoistraživačke i projektne nastave“, u Tehnika i informatika u obrazovanju: 4. Internacionalna konferencija (Čačak: Fakultet tehničkih nauka): 1-8.

Vodič kroz ESPB (2009). Beograd: Savet Evrope. 
Nikolina Zobenica

University of Novi Sad

Faculty of Philosophy

nikolina@ff.uns.ac.rs

\section{PROJECT METHOD AS AN EXTRACURRICULAR ACTIVITY: TRANSLATING KARL MARKUS GAUß' TEXTS ON DANUBE}

\section{Summary}

In teaching translation at universities, instructors still mostly use the traditional teaching concept (frontal): translating at home or in the class - reading aloud the translation - discussion - evaluation of the translation. Students translate various texts (non-fiction or fiction), and the choice of texts predominantly depends on the instructor. Because of the strict time framework students mostly translate several paragraphs from a text which they do not know, so that they are not familiar with the context of the passage. However, there are other teaching concepts, or innovative models which can be applied in teaching translation, like project method. At the Department for German studies at the Faculty of Philosophy of University of Novi Sad, a translation project has been organized as an extracurricular activity in which participated BA, MA and PHD students of German language and literature. They translated together (as a team) two essays of a modern Austrian writer, Karl Markus Gauß, from German into Serbian. In this paper the phases of the project, as well as its execution and results have been depicted, analysed and reflected, whereby the opinion of participating students has also been consulted. The project had a great impact on their motivation, language knowledge and translation skill improvements. The communication through social network (Facebook) has facilitated the working process, as the communication and decisions making was transparent and democratic, and all the data accessible all the time. Team work and group decision, as well as time management have also been practiced during the project. The restriction has to be made regarding the freedom the students enjoyed, because the precondition for the participating in such a project should be the existence of strong intrinsic motivation and readiness to invest time and effort in the overall success of the project. Therefore a motivation letter and an entrance translation should be applied as the means of securing the quality of the working process and project results.

Key words: project method, translation project, extracurricular activity, Karl Markus Gauß, literary translation, students.

Primljeno: 4. 4. 2016.

Prihvaćeno: 5. 6. 2016. 